\title{
Primary mucinuous adenocarcinoma of the ovary: a case report
}

\author{
N. Natu, N. Chandwaskar, Sweta Agrawal*, Khushboo Dudani
}

Department of Obstetrics and Gynaecology, Sri Aurobindo institute of Medical sciences, Indore, India

Received: 29 October 2015

Accepted: 19 November 2015

\section{*Correspondence:}

Dr. Sweta Agrawal,

E-mail: msa.sweta@gmail.com

Copyright: ( $)$ the author(s), publisher and licensee Medip Academy. This is an open-access article distributed under the terms of the Creative Commons Attribution Non-Commercial License, which permits unrestricted non-commercial use, distribution, and reproduction in any medium, provided the original work is properly cited.

\begin{abstract}
Ovarian neoplasms are common tumours in females comprising $23 \%$ of all gynecologic tumours and are the most common gynecologic malignancy. Ovarian cancer is primarily a disease of postmenopausal women, the highest number of cases being concentrated in the age group from 50 to 70 years. They are the 5th leading cause of cancer related deaths in women. Primary Mucinuous cystadenocarcinoma of ovary is very rare. Our reported case was 50 years old woman which came in our OPD of Sri Aurobindo Institute of Medical Sciences with vague symptoms of lower abdominal pain and swelling. The data were collected by history-taking, clinical examination, laboratory investigations, ultrasonographic examination, CECT abdomen, CA 125, and by histo-pathological study of the excised surgical specimen. The case was reported as a rare ovarian mucinous cystadenocarcinoma. New and improved screening modalities are required for early diagnosis. And proper diagnostic criteria should be made for better prognosis.
\end{abstract}

Keywords: Primary mucinuous cystadenocarcinoma, Ovarian neoplasms, CECT abdomen, CA-125, Histopathological report, Screening

\section{INTRODUCTION}

A female's risk at birth of having ovarian tumor sometime in her life is 6-7\%, ${ }^{1}$ Ovarian neoplasms are common tumours in females comprising $23 \%$ of all gynecologic tumours and are the most common gynecologic malignancy. ${ }^{2}$ Ovarian cancer is primarily a disease of postmenopausal women, the highest number of cases being concentrated in the age group from 50 to 70 years. ${ }^{3,4}$ They are the 5 th leading cause of cancer deaths in women. ${ }^{5}$

The main reason for this poor outcome is the inability to diagnose the disease early. Hence, majority of the patients present with late stage disease. Early manifestations of ovarian carcinoma are vague and nonspecific with patients complaining of lower abdominal discomfort, dyspepsia, indigestion and other mild lower gastrointestinal disturbances. Abdominal pain, swelling or a large palpable mass, when present, signify advanced stages of the disease. Recent studies have reported that 95\% of women with ovarian carcinoma have symptoms although not of gynecological nature. ${ }^{6,7}$

The incidence of primary mucinous adenocarcinoma is low. ${ }^{8}$ Mucinous carcinomas are reported to comprise 6$25 \%$ of ovarian carcinomas (mean $12 \%$ ), but recent refinements in the interpretation of histology features of noninvasive and metastatic mucinous carcinomas suggest that this may be an overestimate. ${ }^{9}$ Primary mucinous adenocarcinoma is characterized by a large unilateral ovarian mass with a smooth external surface Metastatic mucinous adenocarcinoma is more likely bilateral and shows a multinodular external surface. The cut surface of the metastatic lesion varies from completely solid to multicystic, mimicking the primary ovary mass. Findings of ovarian capsular implants, vascular invasion, a nodular growth pattern, and infiltrative growth of individual glands or single cells on microscopic examination favor metastasis. ${ }^{10}$ The American Journal of Surgical Pathology 
used simple algorithm which classified mucinous adenocarcinomas of the ovary as primary when they were unilateral $>$ or $=10 \mathrm{~cm}$ and as metastatic when they were unilateral $<10 \mathrm{~cm}$ or bilateral. ${ }^{9}$ We have described an usual primary adenocarcinoma of ovary which within 3 months of span became a huge mass and responded very well to the cytoreduction and surgical treatment.

\section{CASE REPORT}

A 50 year old parous menopausal woman, presented in the OPD with the complain of pain in abdomen since 3 months and lump in abdomen since 3 months. In the beginning lump was very small in size and has grown gradually over the past 3 months to present size of tennis ball. No other relevant past medical history and in surgical history she has undergone tubectomy surgery 20 years back. Family history was also not significant.

On clinical examination her vitals are stable and on per abdomen examination it showed solid mass of 16-18 weeks size gravid uterus arising from pelvis. No tenderness and no other organomegaly present. Mild ascites was present. On per speculum examination vaginal mucosa was pale, cervix pulled up. No discharge or bleeding was seen, pap smear was taken.

On per vaginum examination cervix was pulled high up, deviated to left. Firm to hard mass felt in the posterior and lateral fornices exact size of which could not be determined. Uterus was not felt separately. Per rectal examination revealed hard nodules in POD.

USG showed uterus and ovaries are not seen properly. There is large echogenic lesion of about $17 \times 10 \times 10 \mathrm{~cm}$ size seen in the pelvis showing an echoic component. There are multiple hypoechoiec lesion seen in para aortic region. Impression a large complex mass in the pelvis with para aortic lymphadenopathy? Uterine mass? Ovarian mass? CECT Abdomen was advised.

CECT abdomen pelvis study revealed relatively defined, lobulated solid cystic mass lesion in the pelvis, extending in the both adnexa. Both ovaries are not seen separately from the lesion. Superiorly lesion is protruding in the abdominal cavity, RIF region with displacement of the adjacent small bowel loop and rectosigmoid colon with loss of fat planes at places. Inferiorly, moderate compression on the rest of the pelvis structures including uterus, rectum, bladder internal iliac vessels noted with effaced fat planes. Posteriorly both distal ureters appears to be moderately compressed with mild hydronephrosis.

Mild ascites was seen. No obvious peritoneal or omental deposit / implants. No distant metastasis was seen in liver or lungs.

Large complex solid cystic mass of $13.6 \times 11.2 \times 13.5 \mathrm{~cm}$ size. Possibility of ovarian malignancy with metastatic lymphadenopathy seems most likely.
Pap smear report showed inflammatory smear. FNAC was done features of adenocarcinoma and features of malignant effusion (metastic deposits of adenocarcinoma) was reported.

CA 125 showed $1564 \mathrm{U} / \mathrm{ml}$. Cytoreduction with three cycles of chemotherapy was done with paclitexal and unicarb after that again USG was done there was predominantly cystic mass with thick septation, internal echoes. A solid component $11 \times 7 \mathrm{~cm}$ in pelvis abutting uterus. B/L ovaries could not be visualized properly and on color Doppler mass reveals increased vascularity and low resistance flow.

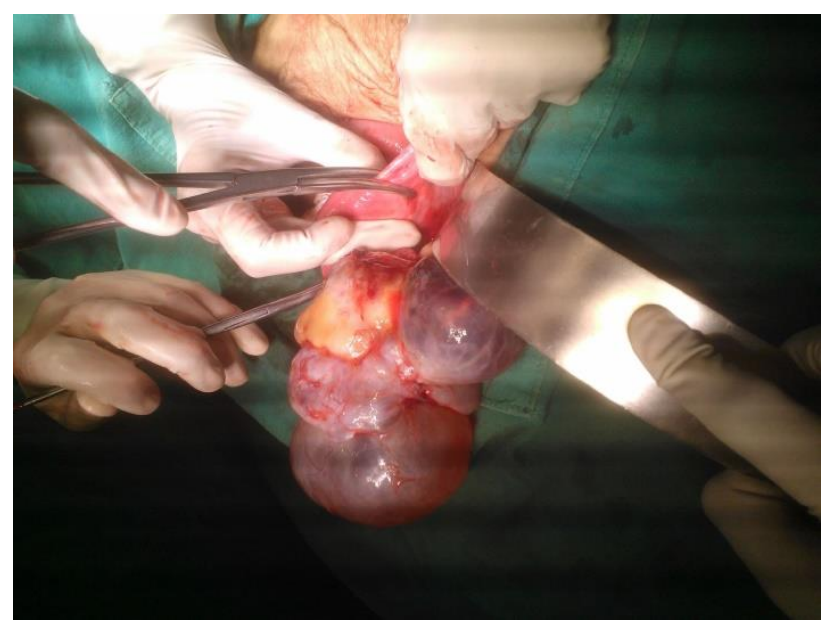

Figure 1: Intraoperative enlarged right sided ovary.

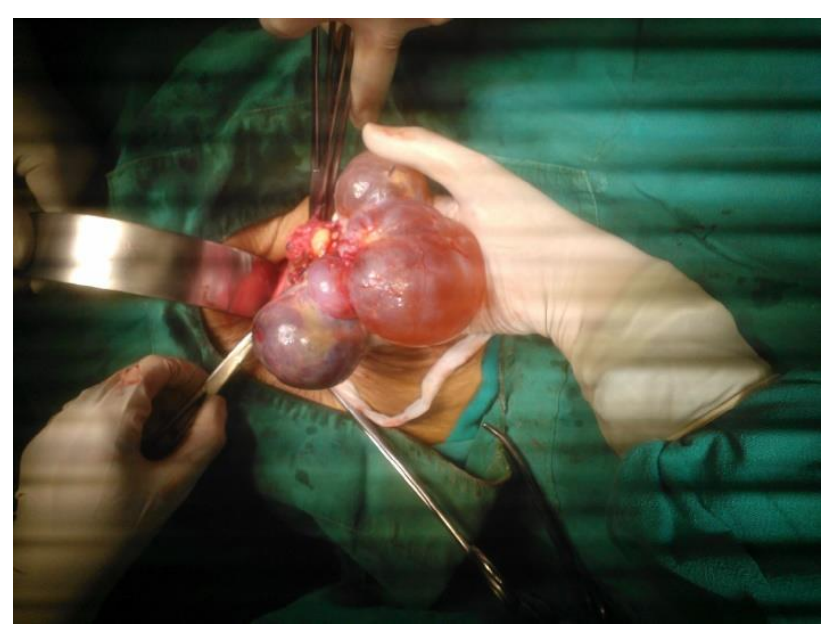

Figure 2: Intraoperative enlarged right ovary.

After cytoreduction case was planned for explorative laprotomy. Intraoperatively Total abdominal hysterectomy and bilateral ovaries were removed, right sided ovary $10 \times 10 \mathrm{~cm}$ irregular shape, flimsy adhesion was present contraletral left ovary was normal no lymph nodes were palpable, ascitic fluid was sent for cytology. Bowel and omentum was normal. 


\section{Histopathology}

Mucinuos cystadenoma carcinoma right ovary and ovarian capsule free of tumour.

5 cycles of chemotherapy of chemotherapy with paclitaxel plus cisplastin.

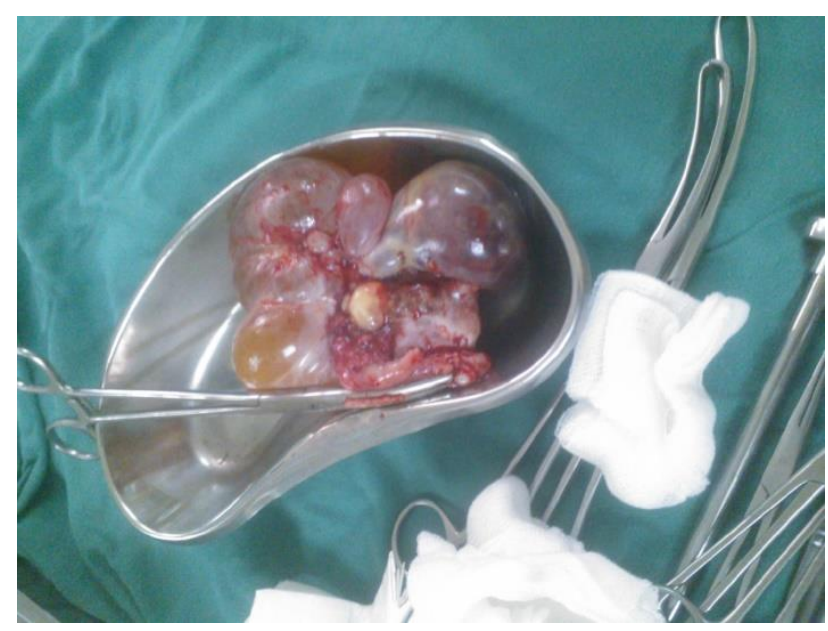

Figure 3: Gross specimen of right sided enlarged ovary.

\section{DISCUSSION}

Ovarian cysts are considered large if they have diameters between 5 and $15 \mathrm{~cm}$ in size ${ }^{11}$ and or between $10 \mathrm{~cm}$ and $20 \mathrm{~cm} .{ }^{12}$ In young people the majority of ovarian cysts decrease in size or even disappear and therefore should be dealt with a careful expectant follow-up by ultrasonography.

Pelvic masses found in women of reproductive and postmenopausal age must be evaluated preoperatively to determine the probability of malignancy. A pelvic mass in a woman of reproductive age may be a functional cyst, particularly if the mass is cystic, less than 6 to 8 centimeters in diameter, unilateral, and mobile. If all of these criteria are present, it is appropriate to re-examine the patient in four to six weeks. If the mass persists or has grown, exploratory laparotomy or laparoscopy is indicated. A woman with a solid or partially cystic mass, ascites, and/or an elevated CA-125 level should be operated on by a gynecologic oncologist or by a surgical team with the necessary skills to surgically stage or debulk the disease. All surgeons who attend women with suspected ovarian malignancy must understand importance of performing appropriate surgical staging and debulking of ovarian cancer. Ovarian cancer is a surgically staged disease. In apparent early-stage disease, complete surgical staging is critical for the selection of adjunctive therapy. In advanced-stage disease, the goal is primary cytoreduction. ${ }^{13}$

Junzo Kigawa ${ }^{14}$ states that Ovarian cancer is one of the most sensitive solid tumours, with objective responses ranging from 60 to $80 \%$ to chemotherapy. In our case initially size was $17 \mathrm{x} 10 \mathrm{x} 10 \mathrm{~cm}$ which regressed to $11 \mathrm{x} 7$ $\mathrm{cm}$ after chemotherapy. Usually primary mucinuous cystadenocarcinoma are unilateral and in our case it was unilateral in orgin. ${ }^{9}$ Primary mucinous carcinoma of the ovary were usually larger, unilateral, had an expansile growth pattern with complex papillae and necrotic luminal debris. ${ }^{15}$ In our case management of ovarian tumours depends on the patient's age, the size of the cyst and its histo-pathological nature. Conservative surgery as ovarian cystectomy and salingo-oophorectomy is adequate for benign lesions and for malignant lesions ${ }^{16}$ cytoreduction followed by exploratory lapratomy and then chemotherapy is necessary.

The rate of recurrence following conservative and radical surgical procedures in low-stage and low-grade tumours are $9 \%$ and $11.6 \%$, respectively; and disease-free and overall survival rates do not differ significantly. ${ }^{17}$ Our patient has completed the family and to avoid recurrence bilateral ovaries along with the uterus was removed. After surgery, the patient should be followed-up carefully as some tumours recur. ${ }^{18}$ Our patient was given appointment for chemotherapy with carboplastin and cisplastin the standard treatment for ovarian cancer.

\section{CONCLUSIONS}

Ovarian tumours are leading cause of death in developing country. Every woman after the age of 45 years should go for screening for gynecological malignancies and it is compulsory for the patients who already have family history of cancer. And more research in the field for gold standard test for ovarian tumours should be done. So that we can omit exploratory lapratomy. Better awareness and screening modalities are needed in the cases of pelvic masses diagnosed clinically.

\section{Funding: No funding sources \\ Conflict of interest: None declared \\ Ethical approval: Not Required}

\section{REFERENCES}

1. Jha R, Karki S. Histological pattern of ovarian tumors and their age distribution. Nepal Med Coll J. 2008;10(2):81-5.

2. Merino MJ, Jaffe G Age contrast in ovarian pathology. Cancer, (Supplement). 1993;7:537-44.

3. Pecorelli S, Odicino F, Maisonneuve P. Carcinoma of the ovary. J Epidemiol Biostats. 1998;3:75-10.

4. Rubin S, Fennelly D, Randall ME. Ovarian cancer. In: Pazdur R, Coia L, Wagman L, Hoskins W,editors. Cancer management: a multidisciplinary approach. Huntington, NY: PRR Inc. 1996.185-205.

5. National Center for Health Statistics, Division of Vital Statistics (Provisional Data). Hyatsville, MD. 1989.

6. Friedman GD, Skilling JS, Udaltsova NV, Smith LH. Early symptoms of ovarian cancer: a case control 
study without recall bias. Fam Pract. 2005;22:54853.

7. Lataifeh I, Marsden DE, Robertson G, Gebski V, Hacker NF. Presenting symptoms of epithelial ovarian cancer. Aust N Z J Obstet Gynaecol. 2005;45:211-4.

8. Jung ES, Bae JH, Lee A, Choi YJ, Park JS, Lee KY. Mucinous Adenocarcinoma Involving the Ovary: Comparative Evaluation of the Classification Algorithms using Tumor Size and Laterality. J Korean Med Sci. 2010;25(2):220-5.

9. Seidman JD1, et al, Primary and metastatic mucinous adenocarcinomas in the ovaries: incidence in routine practice with a new approach to improve intraoperative diagnosis. Am J Surg Pathol. 2003;27(7):985-93.

10. Harrison ML, Jameson C, Gore ME. Mucinous ovarian cancer. Int J Gynecol Cancer. 2008;18:20914.

11. Jones DR, Vasilakis A, Pillai L, Timberlake GA. Giant, benign, mucinous cystadenoma of the ovary: case study and literature review. Am Surg. 1992;58:400-40.

12. Göçmen A, Atak T, Uçar M, Sanlikal F. Laparoscopy-assisted cystectomy for large adnexal cysts. Arch Gynecol Obstet. 2009;279(1):17-22.

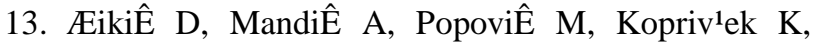
PanjkoviE $\hat{E}$. Metastatic spread of mucinous cystadenocarcinoma of the ovaries into abdominal wall. Arch Oncol. 2005;13(2):86-8.

14. Kigawa J. New Strategy for Overcoming Resistance to Chemotherapy of Ovarian Cancer. Yonago Acta Med. 2013;56(2):43-50.

15. Bhat G, Linu AJ. Mucinous cystadenocarcinoma of ovary: Changing treatment paradigms. World J Obstet Gynecol. 2012;1(4):42-5.

16. Alobaid AS. Mucinous cystadenoma of the ovary in a 12-year-old girl. Saudi Med J. 2008;29(1):126-8.

17. Ayhan A, Celik H, Taskiran C, Bozdag G, Aksu T. Oncologic and reproductive outcome after fertilitysaving surgery in ovarian cancer. Eur J Gynaecol Oncol. 2003;24(3-4):223-32.

18. Ozgun MT, Turkyilmaz C. A giant ovarian mucinous cystadenoma in an adolescent: a case report. Arch Med Sci. 2009;5(2):281-3.

Cite this article as: Natu N, Chandwaskar N, Agrawal S, Dudani K. Primary mucinuous adenocarcinoma of the ovary: a case report. Int $\mathbf{J}$ Reprod Contracept Obstet Gynecol 2015;4:2107-10. 